\title{
풍력타워용 부스덕트 포설시스템 개발 \\ Development of the Bus Duct Installation System for Wind Tower
}

\author{
이 희 남. 이 준 근*.김 봉 석**.박 성 희** \\ Huinam Rhee, Joon Keun Lee, Bong-Seok Kim and Seong-Hee Park
}

(Received August 30, 2013 ; Revised February 12, 2014 ; Accepted February 12, 2014)

Key Words : Wind Tower(풍력타워), Bus Duct System(부스닥트 시스템), Seismic Test(내진시험), Vibration Durability(진동 내구성) Test, Modal Analysis(모드시험)

\begin{abstract}
A bus duct system for wind tower is introduced. A marine cable has been widely used in wind tower or various offshore structures. However, as the electric load capacity is increases, large number of cable lines must be used to cover the huge amount of electric capacities. Therefore, the installation of the cable lines becomes very difficult due to the heavy weight and volume of the cables. On the other hand, by using a single bus duct system line, the power capacity amount of 16 cables can be delivered with significantly compacted form. However, unlike flexible cables, the bus duct is relatively stiff which could generate the resonance phenomenon in the operating condition of the wind tower. In this study, the vibration characteristics of the bus duct are investigated and its long-term reliability during the life time of the wind tower is verified.
\end{abstract}

\section{기 호 설 명}

$$
\begin{aligned}
& a_{p} \text { : 증폭비 } \\
& F_{a, v}: \text { 지반 가속도 계수 } \\
& F_{P} \text { : 설계기반 가진력 } \\
& f_{R} \text { : 최대 회전속도 } \\
& f_{R, m} \text { : 로터날개의 깃 통과 주파수 } \\
& h \text { : 구조물의 평균 루프 높이 } \\
& I_{P}: \text { 주요 부품의 중요도 계수 } \\
& S_{s}: 0.2 \text { 초 주기 이내의 최대 지진응답 크기 } \\
& S_{1}: 1 \text { 초 주기 이내의 최대 지진응답 크기 }
\end{aligned}
$$

\footnotetext{
† Corresponding Author; Member, Dept of Mechanical \& Aerospace Engineering, Sunchon National University E-mail : hnrhee@sunchon.ac.kr Tel : +82-61-750-3824, Fax : +82-61-753-3962

* CAE Research Group, LS Cable \& System ** Busduct Production Team, LS Cable \& System
}

\section{1. 서 론}

알루미늄 도체를 사용하는 부스덕트는 기존 케이 블 대비 경량화 및 compact성 그리고 포설 편의성 을 확보할 수 있다는 장점이 있으므로 최근 산업현 장에 활발하게 적용되고 있다. 그러나 수백 $\mathrm{m}$ 이상 의 연속성을 갖는 케이블과 달리 부스덕트는 일반적 으로 $3 \mathrm{~m}$ 길이의 피더와 이를 연결하는 접속함으로 구성되므로 케이블 대비 진동 및 피로 등에 취약한 구조라고 할 수 있다. 특히 초고층 빌딩이나 풍력타 워, 선박 등과 같이 동적인 하중을 받는 현장에 포 설을 위해서는 전기적인 안정성 확보 이외에 구조적

\# A part of this paper was presented at the KSNVE 2012 Annual Spring Conference

\# Recommended by Editor Hyung-Jo Jung

(c) The Korean Society for Noise and Vibration Engineering 
인 진동 내구성을 동시에 검증해야 하며 이러한 구 조/진동측면에서 효율적으로 내구를 검증하는 방법 을 도출하는 것이 중요하다고 할 수 있다. 따라서 이 연구에서는 풍력타워에 이 부스덕트 시스템이 적 용될 수 있도록 해석을 통해 사전 구조/진동적인 안 정성을 확인하였으며 실제 실증시험을 통해 장기내 구를 포함한 구조/진동안정성을 검증하였다

\section{2. 부스덕트 시스템}

\section{1 부스덕트 시스템의 특징}

케이블은 통상 Fig. 1처럼 케이블 트레이에 설치 하게 되는데 전류 부하용량이 클수록 적층구조로 되 므로 공간상의 제약이 있는 곳에는 포설에 어려움이 있게 된다. 반면 부스덕트 시스템을 적용할 경우에 는 1 개 라인으로 대전류 전송이 가능하므로 $\mathrm{com}-$ pact 한 특성을 확보할 수 있음은 물론이고 동 도체 를 사용하는 케이블과는 달리 알루미늄 도체를 사용
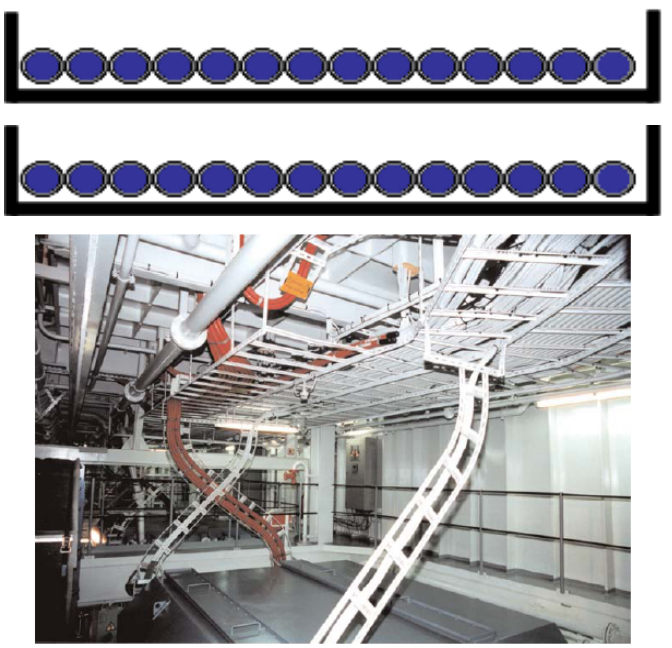

(a) Cable installation

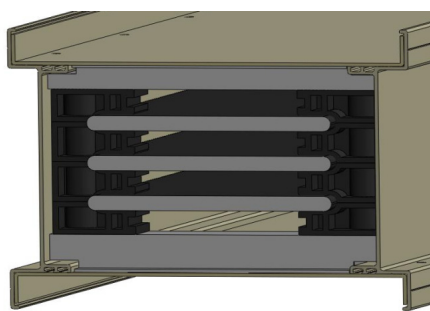

(b) Bus duct installation

Fig. 1 Cable \& bus duct installation
하므로 경량화는 물론이고 원재료비 상승에 대한 원 가반영 비율을 최소화 할 수 있으므로 제품의 원가 경쟁력도 확보할 수 있는 장점이 있다. Fig. 1(b)처 럼 부스덕트 내부는 $\mathrm{R}, \mathrm{S}, \mathrm{T}$ 3상이 에폭시 절연물 로 코팅처리 되어있고 각 상은 $340 \mathrm{~mm}$ 이상의 절연 지지물로 고정되어 상간 혼촉에 의한 절연품질문제 를 사전에 방지하도록 설계되었다. Fig. 2처럼 케이 블의 일반적인 전원 분기방식은 일대일 대응 방식을 적용하므로 대용량 전류 배전의 경우 많은 가닥수의 케이블이 필요하지만 부스덕트 시스템을 활용할 경 우 메인라인 중간 중간에 plug-in box를 분기시켜 배전하면 되므로 매우 편리한 시스템이라고 할 수 있다. Fig. 3은 부스덕트와 plug-in box 형상을 보여 준다.

\section{2 풍력타워용 부스덕트 내진요건}

풍력타워는 일반적으로 선급기준인 GL Guideline 2003 의 규정을 준수하여 설계되어야 한다. 식 (1)과 같이 로터의 운전주파수가 타워의 공진주파수의 95 $\%$ 수준보다 낮아야 하며 blade passing frequency (BPF) 대비 각 $n$ 차에 해당되는 타워의 고유진동수 가 $95 \%$ 이하가 되도록 설계되어야 한다.

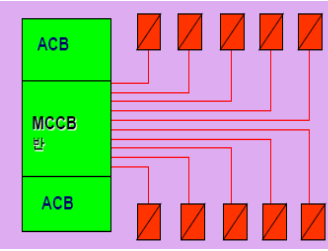

(a) Cable array

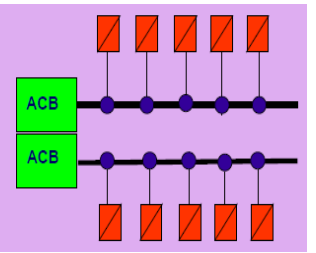

(b) Busduct array
Fig. 2 Power distribution for cable \& bus duct

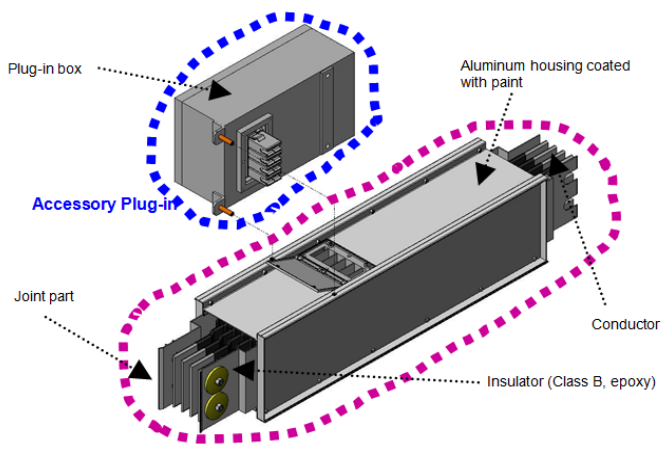

Fig. 3 Bus duct line \& plug-in box 


$$
f_{R} / f_{0,1} \leq 0.95
$$

and

$$
f_{R, m} / f_{0, n} \leq 0.95 \text { or } f_{R, m} / f_{0, n} \geq 1.05
$$

$f_{R} \quad$ : Maximum rotational speed of the rotor in normal operation

$f_{0,1}$ : First natural frequency of the tower

$f_{R, m}$ : Blade passing frequency of $\mathrm{m}$ rotor blades $f_{0, n}: n$-th natural frequency of the tower

이러한 요건은 풍력타워에 대한 내구를 별도의 가진시험을 통해서 검증하기가 어려우므로 이러한 설계 가이드라인을 통해 공진을 유발하는 직접적인 운전조건에 놓여있지 않다는 것을 만족할 수 있도록 규정으로 정해놓았다고 이해할 수 있다. 그러나 부 스덕트와 같이 풍력타워 내부에 장착된 전장품은 내 부의 주기적인 경계조건에 의해 지지되며 따라서 주 로 풍하중 등 저주파 하중에 의한 가진력과 동시에 상단 너셀부위에서 발생하는 중 주파수 대역 이상의 가진력을 동시에 받게 된다. 또한 최근 국제적인 이 슈가 되고 있는 지진파 성분도 가진력의 한 종류가 될 수 있다. 따라서 이러한 전반적인 가진력의 종류 를 고려한 타워 내부의 전장품에 대한 장기적인 내 구검증이 필요하다고 할 수 있다. Fig. 4는 풍력타워 에 부스덕트를 적용하는 일례이다. 풍력타워내에서 부스덕트를 적용할 수 있는 구간은 너셀 하단의 loop 케이블과 지면 기초부의 변압기 구간이다. Fig. 5는 support-damper 시스템을 고려한 구조해석 결 과이며 이와 같이 부스덕트 본체를 support-damper 로 포설해야 풍하중 및 감쇠기능을 통해 진동에너지 를 흡수할 수 있으므로 장기적인 진동내구성을 확보 할 수 있게 된다. Table 1은 내구시험에 적용되는
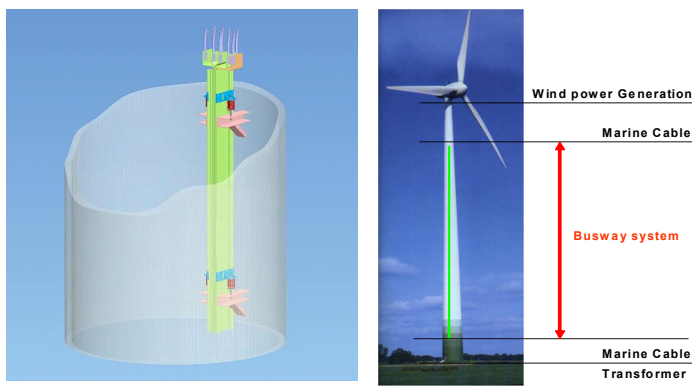

Fig. 4 Schematic installation of bus duct
선급기준의 피로시험방법이다.

Fig. 6은 실제 풍력타워에 포설된 부스덕트 시스 템이다. 케이블 포설시 너셀부위까지 케이블 드럼을
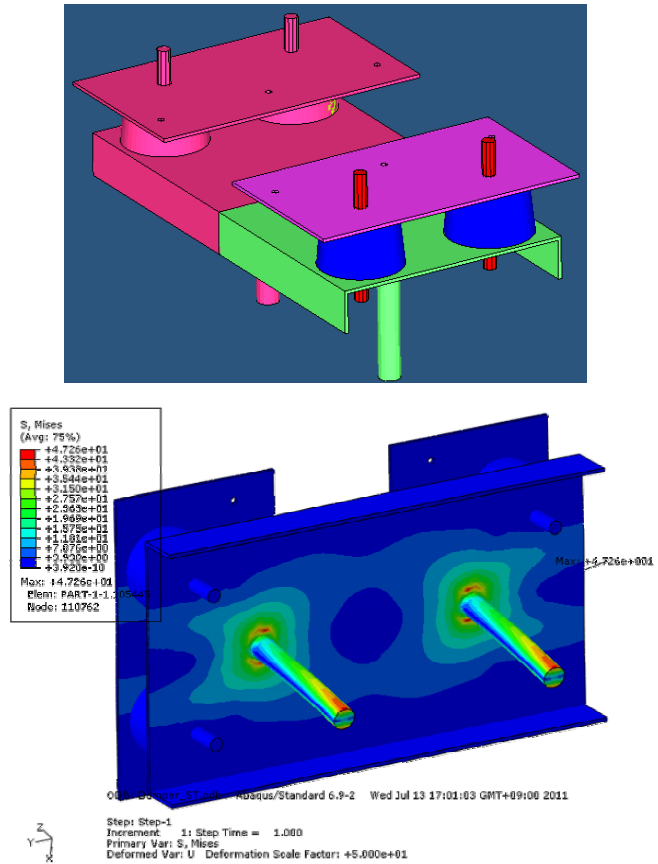

Fig. 5 Damper-support installation system

Table 1 Vibration durability test for bus duct system

\begin{tabular}{c|c}
\hline \hline No & Item \\
\hline 1 & IACS UR E10 test item No. 7 \\
\hline 2 & $2 \mathrm{~Hz}$ to $13.2 \mathrm{~Hz}$ with amplitude $1 \mathrm{~mm}$ \\
\hline 3 & $13.2 \mathrm{~Hz}$ to $100 \mathrm{~Hz}$ with acceleration $0.7 \mathrm{~g}$ \\
\hline 4 & $\begin{array}{c}\text { Amplification factor (Q) should be less than } \\
10 \text { to prevent resonance damage }\end{array}$ \\
\hline 5 & 90 min excitation at each resonance frequency \\
\hline
\end{tabular}

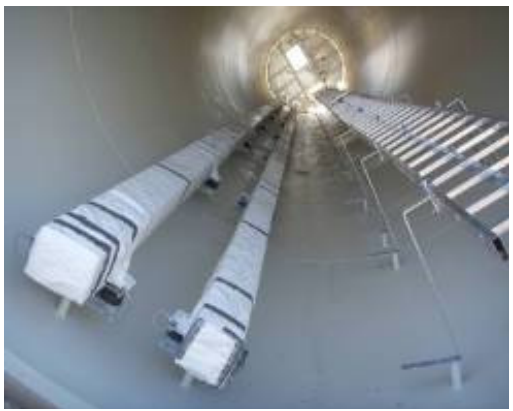

Fig. 6 Bus duct installation on tower section 
올려서 포설해야 하므로 타워 섹션별로 별개 포설하 는 부스덕트에 비해 작업 난이도 및 설치시간이 매 우 길어진다. 그러나 부스덕트를 풍력타워에 적용할 경우 용량별로 차이는 있으나 평균 $50 \%$ 이상의 포 설기간을 단축할 수 있는 장점이 있다.

\section{3 부스덕트 내구검증}

(1) IBC 2003/ASCE 7-02 requirement ${ }^{(1)}$

$$
S_{D S}=\frac{2}{3} F_{a} S_{s}, \quad S_{D 1}=\frac{2}{3} F_{v} S_{1}
$$

$F_{a, v}:$ Acceleration on based coefficients

$S_{s} \quad$ : Mapped spectral response $0.2 \mathrm{sec}$ period

$S_{I} \quad$ : Mapped spectral response $1 \mathrm{sec}$ period

식 (2)에서 $0.2 \mathrm{sec}$ 및 $1 \mathrm{sec}$ 에서의 최대가속도는 $2.56 \mathrm{~g}$ 와 $1.24 \mathrm{~g}$ 이고 지반계수를 각각 1 과 1.5 로 가 정하면 식 (2)를 다음과 같이 표현 할 수 있다.

$$
\begin{aligned}
& S_{D S}=\frac{2}{3} \times 1 \times 2.56 g=1.71 g, \\
& S_{D 1}=\frac{2}{3} \times 1.5 \times 1.24 g=1.24 g
\end{aligned}
$$

식 (3)에서 보는 것처럼 IBC 2003 기준의 최대 지반하중은 각각 $1.71 \mathrm{~g}$ 와 $1.24 \mathrm{~g}$ 로 구분할 수 있다. 다시 IBC Code 중 Section 1621.1에 보면 전장품 에 대한 내진검증 기준이 제시되는데 이것은 다시 $\mathrm{ASCE}$ 7-02와 연계되어 다음의 식으로 표현된다.

$$
F_{P}=\frac{0.4 a_{P} S_{D S} W_{P}}{R_{P} / I_{P}} \times\left(1+2 \frac{z}{h}\right)
$$

$F_{P} \quad:$ Seismic design force

$a_{p} \quad$ : Amplification factor (1 2.5)

$W_{p}$ : Components operating weight

$R_{P} \quad$ : Response modification factor that varies from 1.0 to $5.0(2.5)$

$I_{P} \quad$ : Components importance factor that is either 1.0 or $1.5(1.5)$

$z \quad$ : Highest point of equipment in a structure relative to grade elevation

$h$ : Average roof height of structure relative to grade elevation

식 (4)를 이용하고 중요한 전장품이라는 가정하에
보수적인 계수를 대입하면 최고층에서의 응답가속도 를 구할 수 있다.

$$
F_{P}=\frac{0.4 \times 2.5 \times 1.7 g}{2.5 / 1.5} \times(1+2)=3.06 g
$$

따라서 $\mathrm{IBC}$ 기준과 $\mathrm{ASCE}$ 7-02 기준에 의거 최대 건물높이에 대한 증폭을 고려할 경우 최대 약 $3 \mathrm{~g}$ 의 지진파를 적용하게 된다.

(2) GR-63 requirement ${ }^{(1)}$

GR-63 규격은 미국 통신설비 내진규격으로 2 5 $\mathrm{Hz}$ 주파수 대역에서 최대 $5.0 \mathrm{~g}$ 의 값을 갖는다.

(3) IEEE 693 Seismic Requirement

Figs. 7, 8은 GR-63 및 IEEE 693 Code에서 제시

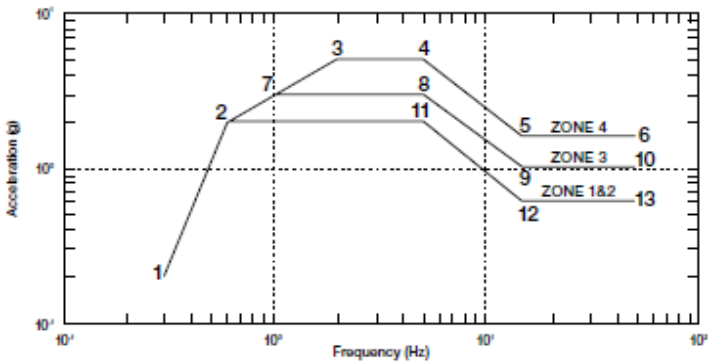

\begin{tabular}{|c|c|c|}
\hline $\begin{array}{c}\text { Coordinate } \\
\text { point }\end{array}$ & Frequency $(\mathrm{Hz})$ & $\begin{array}{c}\text { Values for upper } \\
\text { floor acceleration }\end{array}$ \\
\hline \multicolumn{3}{|c|}{ Zone 4} \\
\hline 1 & 0.3 & 0.2 \\
\hline 2 & 0.6 & 2.0 \\
\hline 3 & 2.0 & 5.0 \\
\hline 4 & 5.0 & 5.0 \\
\hline 5 & 15.0 & 1.6 \\
\hline 6 & 50.0 & 1.6 \\
\hline
\end{tabular}

Fig. 7 GR-63 seismic standards

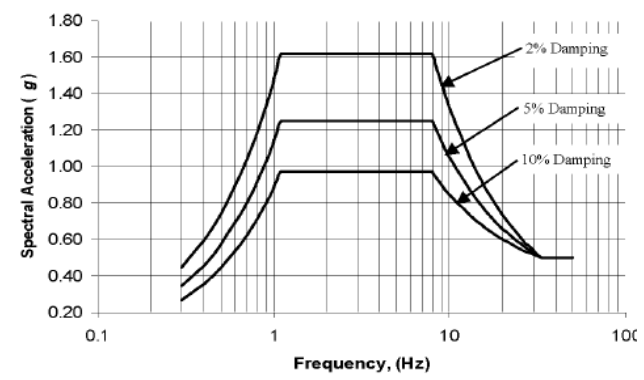

Fig. 8 IEEE 693 seismic standards 
하는 seismic load를 나타낸다. 여기서 seismic load 는 감쇠값에 따라 크게 3 단계로 구분하는데 특히 $2 \%$ 감쇠값에서 최대 $1.6 \mathrm{~g}$ 수준의 가속도 값을 갖게 된다. 현재 세계적으로 적용되는 내진요건 중에 가장 높은 값은 GR-63의 최대 $5 \mathrm{~g}$ 가속도 조건이라고 할 수 있다. 앞서 말한 바와 같이 IBC 2003/ASCE 7-02/GR-63/IEEE $693^{(1)}$ 을 포괄하는 지진파 스펙트 럼을 모두 포괄하는 값으로 내진신호를 만들어서 시 험한다면 매우 유용한 값으로 광범위하게 적용할 수

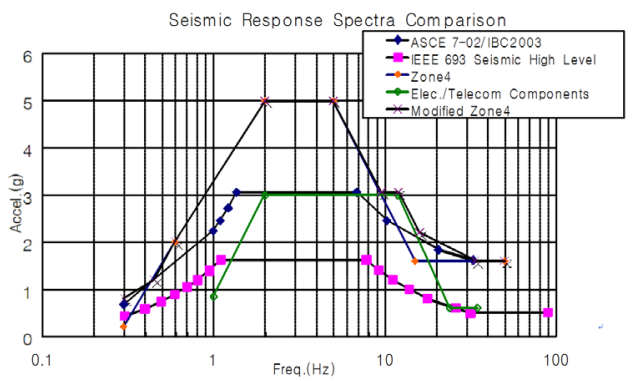

Fig. 9 Encompassed input data for seismic test

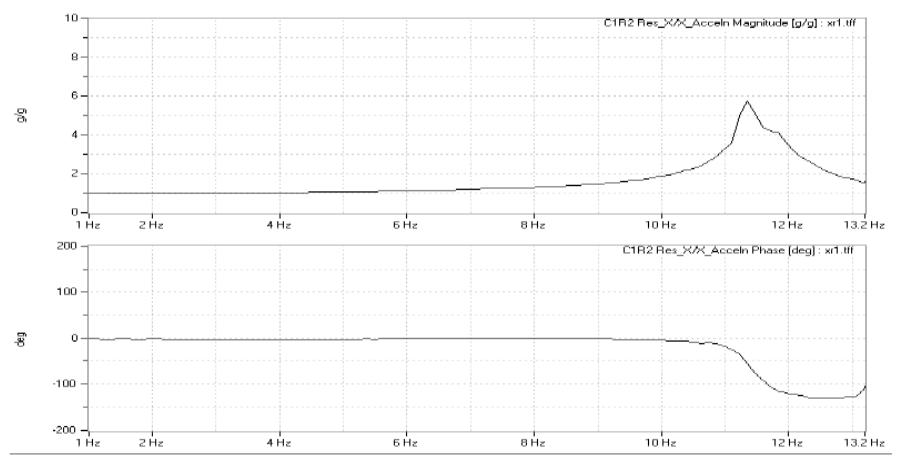

(a) X-direction

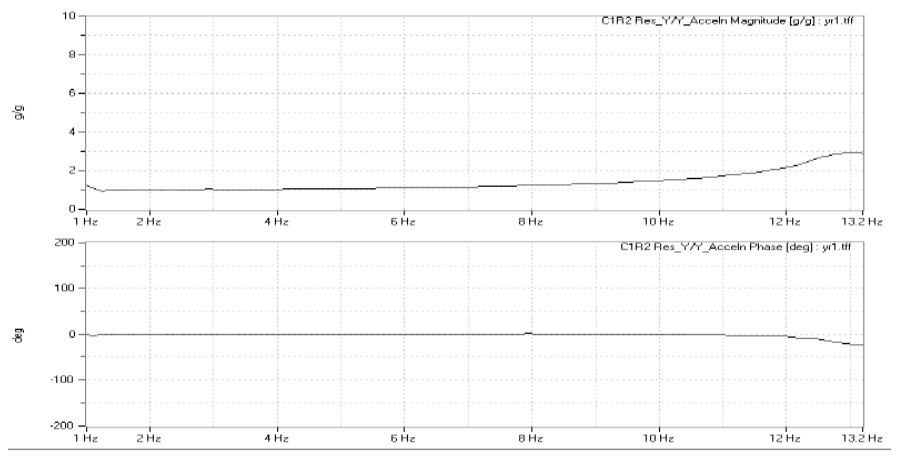

(b) Y-direction

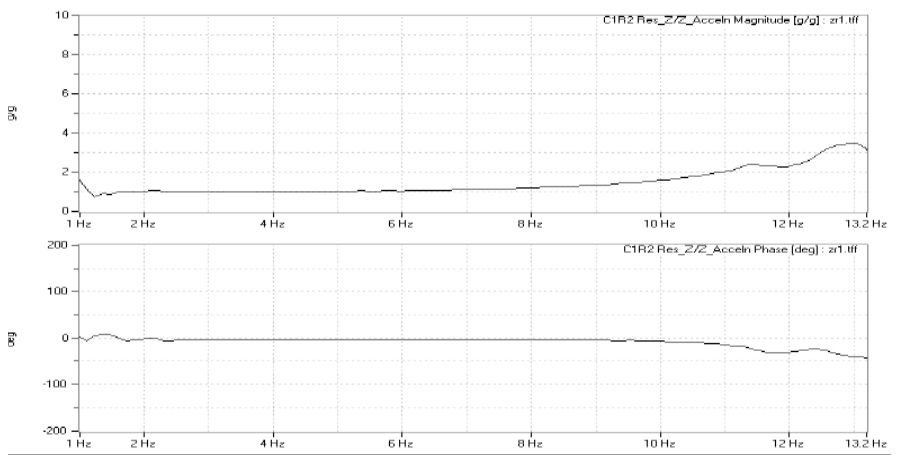

(c) Z-direction

Fig. 10 FRF from resonance search tests 
있을 것이다. Fig. 8은 이러한 내진 code를 모두 포 괄하는 지진파 스펙트럼이다.

각 내진요구 스펙트럼 중 GR-63 규정이 가장 높은 피크값을 가지나 $10 \mathrm{~Hz}$ 이상의 주파수 대역에서는 IBC 2003/ASCE 7-02 스펙트럼값이 상대적으로 높 은 영역이 존재하므로 $50 \mathrm{~Hz}$ 이내 주파수 범위에서

Table 2 Seismic test procedures per IEEE $693^{(2)}$

1. Receipt and inspection; visual inspection

2. Hi-voltage electrical testing; $(1000+2 \mathrm{U})+5 \mathrm{~V}(\mathrm{RMS})$ for $60 \mathrm{sec}$

3. Insulation resistance testing ; (IEC 60439)

4. Resonance sine sweep test $1 \sim 50 \mathrm{~Hz}$

5. Seismic test of Zone $2 / 3 / 4$ with $2 \%$ damping ; tri-axial random testing

6. Resonance search testing $(\mathrm{Re})$ : Sine sweep

7. Hi-voltage electrical testing $(\mathrm{Re})$

8. Insulation resistance testing $(\mathrm{Re})$

9. Final inspection : structural failure, deformations etc.
가장 높은 값을 포괄할 수 있도록 신호를 생성하였 으며 특히 2009년 10월에 발효된 전기통신설비 내 진검증 기준에 의거한 내진 스펙트럼도 포함하여 지 진파 시험기준으로 하였다. 시험절차는 IEEE 693의 내진시험기준인 Table 2와 같다.

Fig. 10은 Fig. 11과 같은 포설 조건하에서의 공진 검색시험결과이다. Table 3처럼 각각 $\mathrm{X}$ 방향으로는 $11.4,31.9,42.1 \mathrm{~Hz}$ 의 공진주파수를 가지며, $\mathrm{Y}$ 방향으 로는 $14.2,16.4 \mathrm{~Hz}, \mathrm{Z}$ 방향으로는 $14.2,57.9 \mathrm{~Hz}$ 의 고유 진동수를 확인하였다. 실험으로 구한 각 방향의 모드 를 해석결과와 비교하면, 1,2 차 모드는 $26.7 / 38,1 \mathrm{~Hz}$ 로

Table 3 Natural frequencies for 3-axis

\begin{tabular}{c|c|c|c}
\hline \hline & $\begin{array}{c}\text { Resonant } \\
\text { freq.(Hz) }\end{array}$ & $\begin{array}{c}\text { Damping } \\
\text { factor(\%) }\end{array}$ & $\begin{array}{c}\text { Amplification } \\
\text { factor }\end{array}$ \\
\hline X-Dir. & $\begin{array}{c}11.35 / 31.98 \\
/ 42.11\end{array}$ & $\begin{array}{c}3.23 / 5.34 / \\
2.32\end{array}$ & $\begin{array}{c}5.75 / 3.29 / \\
3.20\end{array}$ \\
\hline Y-Dir. & $14.16 / 16.36$ & $8.19 / 8.58$ & $4.18 / 4.30$ \\
\hline Z-Dir. & $14.16 / 57.86$ & $6.03 / 0.74$ & $6.99 / 2.34$ \\
\hline
\end{tabular}
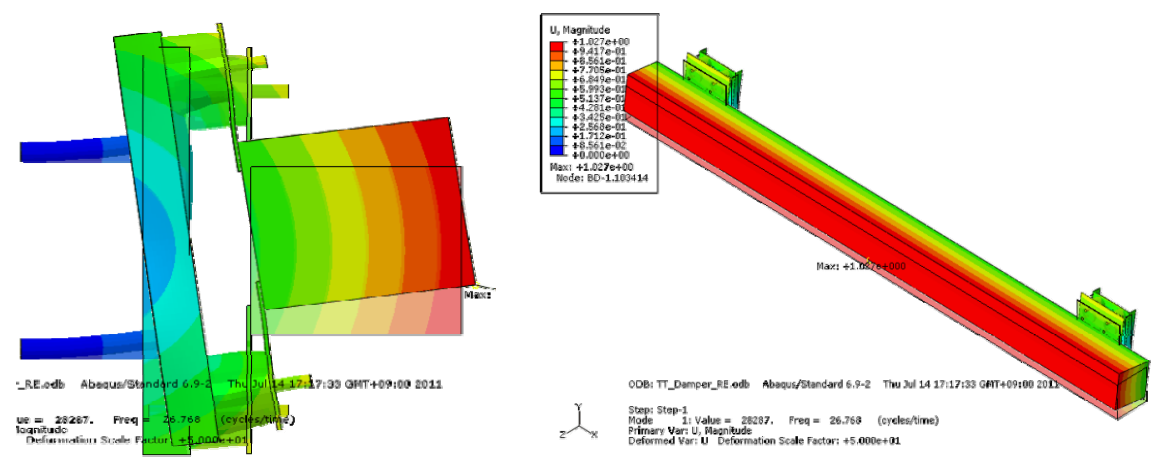

(a) Rigid-bending mode
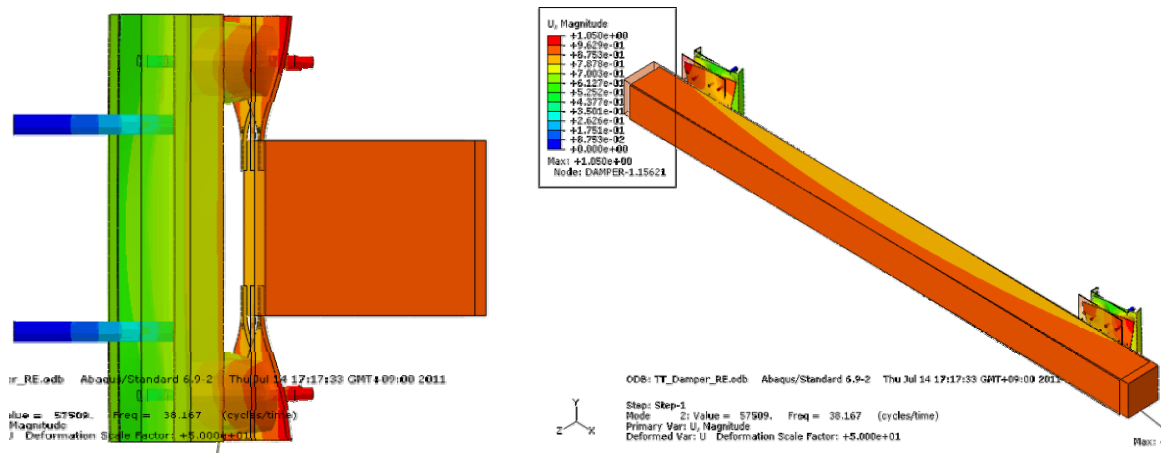

(b) Rigid-torsion mode

Fig. 11 Vibration mode for bus trunk duct 
마운트의 강체-굽힘/비틀림 모드임을 알 수 있다. 이 것은 damper-support 조건을 사용하는 풍력타워용 부스덕트의 기본 모드 특성이라고 할 수 있다. 즉 풍력타워에서 발생하는 여러 진동을 결과적으로 damper-support 시스템이 흡수해 주는 구조이기 때 문에 발생하는 현상이다.

이러한 각 방향의 공진주파수를 기준으로 Table 1 의 진동피로 내구 시험을 실시하게 된다. 이러한

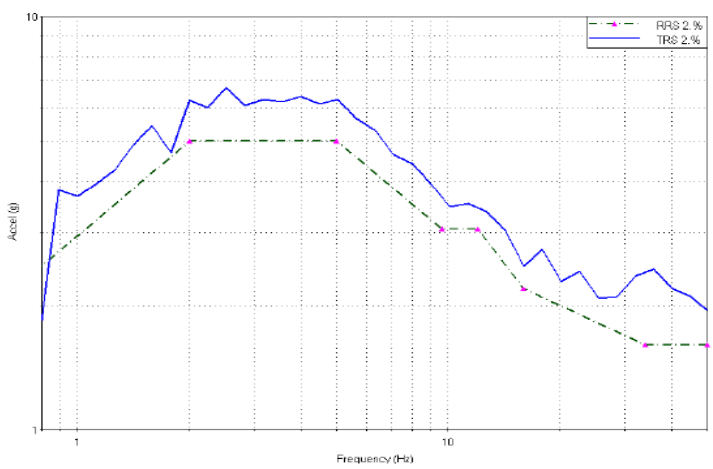

(a) X-direction

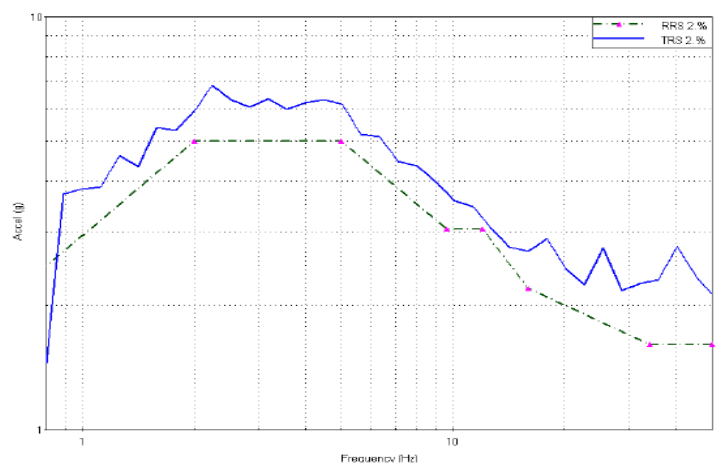

(b) Y-direction

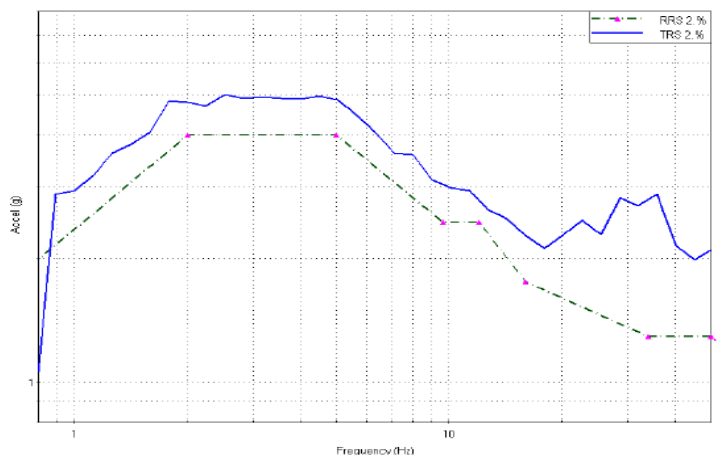

(c) Z-direction

Fig. 12 Comparison of TRS \& RRS(zone 4 test)
피로시험 이후에는 Table 2의 내진시험 procedure를 따라서 내진 zone 2 4의 시험을 하게 되는데 가진 Table에서 각 3축 방향의 지진파 가진신호를 모니 터링 하여 규정의 값 이상으로 가진 되었는지 확인 하여야 한다. Fig. 12는 seismic zone 4 조건에서 시 험이 성공적으로 수행되었는지 모니터링 한 결과 $\left(\mathrm{TRS}^{(3)}\right.$ : test response spectra)를 요구입력신호 $\left(\mathrm{RRS}^{(3)}\right)$ 와 비교한 결과이며 Fig. 12와 같이 TRS가 $\mathrm{RRS}$ 를 3축 조건에서 충분히 포괄하고 있음을 확인 할 수 있다.

Fig. 13은 풍력타워용 부스덕트 포설조건을 모사 하여 실증 가진 시험을 하기 위한 set-up이다. 시험 절차는 Table 2의 절차를 따랐으며 vibration fatigue 및 내진시험을 연속적으로 수행하여 피로 및 내진내 구 성능을 동시에 검증할 수 있었다. 즉, Table 2에 따른 시험 완료 후 최종 단계로서 구조적 결함이나 과도한 변형 발생여부를 검사하여 이상이 없음을 확 인할 수 있었다.

Fig. 14는 진동피로 내구 및 내진성능실험 후의 damper 형상 및 기계적인 물성이며 실험결과 충분 히 양호한 상태임을 확인되었다.

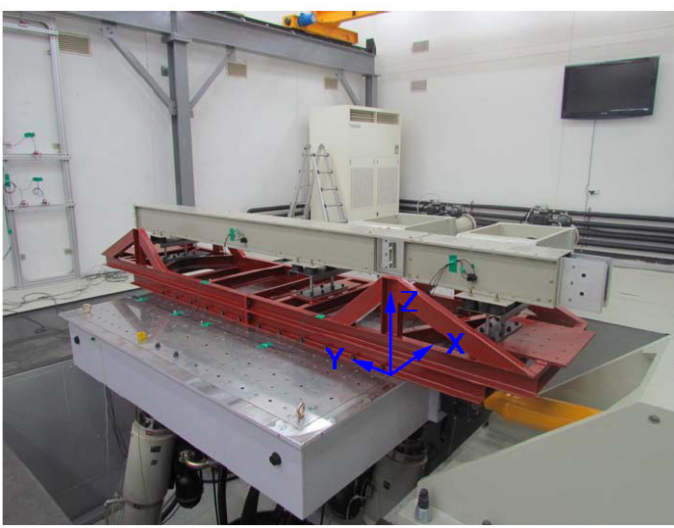

Fig. 13 Seismic \& vibration fatigue test set-up

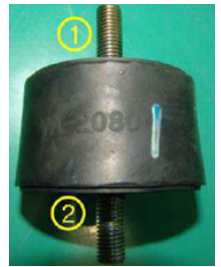

\begin{tabular}{|c|c|c|}
\hline Load & $\begin{array}{c}\text { Displace- } \\
\text { ment }\end{array}$ & Stiffness \\
\hline $3,920 \mathrm{~N}$ & $6.2 \mathrm{~mm}$ & $632.3 \mathrm{~N} / \mathrm{mm}$ \\
\hline
\end{tabular}

* Bus duct damper clearance $2.0 \mathrm{~m}$

Fig. 14 Material properties of damper 


\section{3. 결 론}

이 연구에서는 풍력타워용 부스덕트 개발 및 풍 력타워에서 발생할 수 있는 진동피로 내구 및 최근 이슈가 되고 있는 내진요건, 즉, 건축/토목/전기/통신 에 대한 내진요건을 모두 포괄하여 검증시험을 진행 하였다. 지진파에 의한 공진현상에 의한 파손을 최 소화하기 위해 지진파 피크 영역을 피할 수 있도록 지지부를 설계하였으며 가장 가혹한 내구조건으로 알려져 있는 선급피로기준을 포함한 내구신뢰성 검 증 절차를 수립하여 내진성능을 입증하였다.

\section{References}

(1) IBC 2003/ASCE7-02/IEEE 693-1997/GR-63

(2) Lee, J. and Kim, W. B., 2005, Seismic Qualification Using Modal Analysis and Experimental Techniques, Proceedings of the 12th ICSV, Lisbon, Portugal.

(3) Lee, J. and Beon, H. S., 2002, Seismic Qualification of Main Control Board for Nuclear Power Plant UCN 5\&6, Transactions of the Korean Society for Noise and Vibration Engineering, Vol. 12, No. 11, pp. 856 863.

(4) Nashif, A. D. and Jones, D. I., 1985, Vibration Damping, John Wiley \& Sons, Inc., New York.

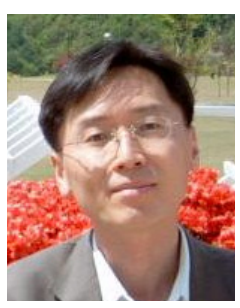

Huinam Rhee received Ph.D. in Mechanical Eng from KAIST in 1998. He has research experiences with Korea Atomic Energy Research Inst and Korea Power Eng Co for 16 years, and is currently a professor with the Dept of Mechanical \& Aerospace Eng at Sunchon National Univ, Korea. His research includes flow-induced vibration, vi- bratory gyroscopes, resonance scattering of waves, vibration control, multi-body dynamic simulation of lunar lander, etc.

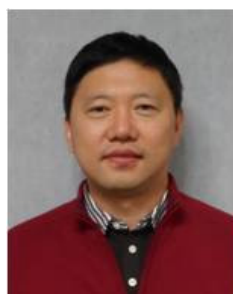

Joon-Keun Lee received the Ph.D. degree in Mechanical Engineering from Inha University in 1997 . He is a Professional Engineer in Noise \& Vibration division since 1997 and got a MBA degree from State University of New York in 2012. He published 18 journal papers and made numerous conference paper presentation internationally. Dr. Lee is currently a Principal Research Engineer in LS Cable \& System, Korea. His research interests are Structural Dynamics/Vibration Control, Rotor Dynamic Analysis, Wave Propagation Mechanics, Seismic Design \& Qualification.

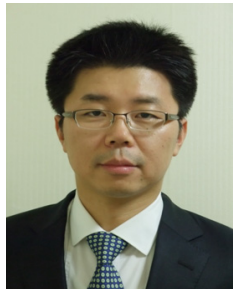

Bong-Suk Kim received the Ph.D. degree in Mechanical Engineering from Ajou University in 2007 and worked at University of Michigan as a Research Fellow from 2007 to 2009. Dr. Kim is currently a Senior Research Engineer at Fundamental Technology Research Center in LS Cable \& System, Korea. His research interests are in the area of Structural Vibration Control, Seismic Qualification Assessment, Cable Dynamics, and Explosion-proof Design.

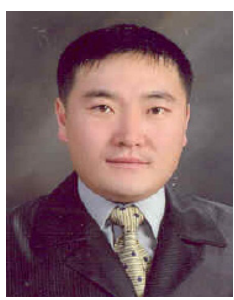

Sung-Hi Park received the Ph.D. degree in Electrical Engineering from Choong-Nam National University in 2005. Dr. Park is currently a Senior Reseach Engineer at Busduct Production Division in LS Cable \& System, Korea. His reserch interests are in the area of High Voltage Insulation in Electrical System. 